\title{
Insulin resistance and changes in chronotropic responses to adrenergic and cholinergic agonists in isolated rat atria
}

\author{
Thippeswamy S. Bor eddy, Basanagouda M. Patil
}

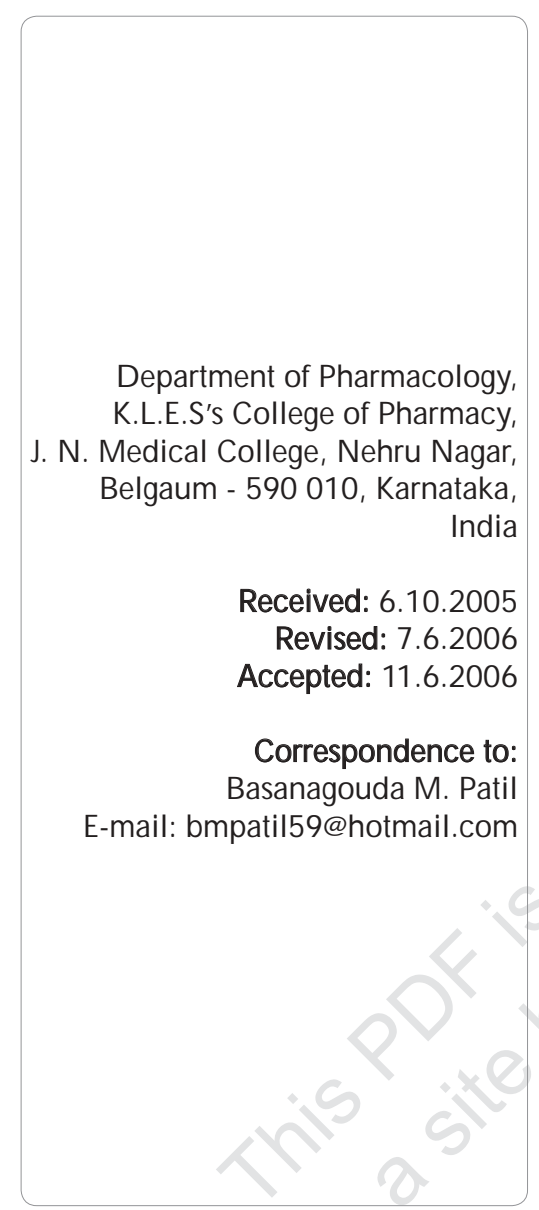

\begin{abstract}
O bjectives: To determine the effects of $\beta$-adrenoceptor and muscarinic agonists on the contractile rate of isolated right atria of rats fed a high fructose diet with or without rosiglitazone (RSG).

Materials and Methods: Male Sprague Dawley rats were assigned to four groups and given ad libitum access to one of the following diets: standard chow, standard chow supplemented with $4 \mathrm{mg} / \mathrm{kg} /$ day RSG, a high fructose diet and a high fructose diet with 4 $\mathrm{mg} / \mathrm{kg} /$ day RSG. All the groups were maintained on these regimens for three weeks with w eekly measurements of systolic blood pressure and body w eight. At the end of the three w eeks, the rats were exsanguinated and the hearts were rapidly removed following which blood glucose, insulin and lipid profiles were estimated. The right atria were isolated from the heart and their responsiveness to sympathetic and parasympathetic agonists was studied.

Results: Basal, spontaneous, isolated atrial pacemaker rate was diminished in fructose-fed rats. The maximum pacemaker rate to isoproterenol or norepinephrine was unchanged in fructose-fed rats. Further, the increase in atrial rate and half maximal effective concentration values for each agent were also unaffected. The sensitivity to negative chronotropic action of acetylcholine was enhanced in fructose fed rats, whereas the response to carbachol was unchanged. The increased sensitivity to acetylcholine was restored by RSG treatment.

Conclusion: High fructose diet induced insulin resistance and hypertension with alterations in basal spontaneous pacemaker, enhanced sensitivity to cholinergic agonist without any changes in the response to adrenergic and cholinergic receptor activation. Treatment with insulin sensitizer rosiglitazone was able to prevent all these changes. The present study suggests that rosiglitazone may have effect on the cardiovascular system in addition to the insulin sensitising action.
\end{abstract}

KEY WORDS: Insulin resistance, $\beta$-adrenoceptor, muscranic receptor, isolated atria, insulin sensitizer
Clinical evidence suggests that insulin resistance (IR) increases cardiovascular risk in patients with type-2 diabetes. ${ }^{[1,2]}$ Detectable cardiac dysfunction has been reported to occur as early as the glucose intolerance phase characterized by hyperinsulinemia and dyslipidemia that follows insulin resistance. ${ }^{[3]}$ Cardiac muscles exhibit insulin resistance in various pathological conditions such as obesity, hypertension and coronary heart diseases. ${ }^{[4-6]}$ Recently, it has been shown that hypertrophied muscle, which develops as a compensatory mechanism during heart failure, also exhibits $I^{|7|}$ and contributes to the progressive deterioration in myocardial function. ${ }^{[8]}$ Insulin direct activates the sympathetic nervous system ${ }^{[9]}$ hence, compensatory hyperinsulinemia developed during IR may contribute towards increased heart rate and hypertension. ${ }^{[10,11]}$ Further, chronic hyperinsulinemia is found to be accompanied by reduced cardiac vagal activity. ${ }^{[12]}$ However, to our knowledge, no data is available regarding the influence of IR on autonomic receptor responsiveness of the heart.

Diabetes and the metabolic syndrome (hypertension, IR and obesity) adversely affect the cardiac autonomic function and are associated with increased risk of cardiovascular events. ${ }^{[13-15]}$ Elevated fasting insulin levels have been shown to increase sympathetic activity and heart rate. ${ }^{[16]}$ The IR syndrome also predisposes individuals to cardiovascular hyperresponsiveness to sympathetic stimulation and has been shown to reduce heart rate variability. ${ }^{[17]}$ Further, chronic 
hyperinsulinemia is associated with heightened sympathetic tone and decreased vagal tone. ${ }^{[18,19]}$ It would be interesting to know whether IR could change the atrial pacemaker rate and autonomic responsiveness of the cardiac tissue. Hence in the present study, a high fructose diet was chosed as a model to induce IR to determine the effect of $\beta$-adrenoceptor and muscaranic agonists on the spontaneous rate of isolated right atria and the effect of rosiglitazone (RSG) on IR-induced changes in atrial pacemaker rate changes and cardiovascular responsiveness to the above agonists.

\section{Materials and Methods}

All the experimental procedures were in accordance with the Committee for the Purpose of Control and Supervision of Experiments on Animals (CPCSEA), Chennai, India. The study was approved by the Institutional Animal Ethics Committee, K.L.E.S's College of Pharmacy, Belgaum, India.

Twelve week-old male Sprague Dawley rats obtained from the National Centre for Laboratory of Animal Sciences, National Institute of Nutrition, Hyderabad, India, were housed individually in a controlled environment with 12-h light / dark cycles and free access to food and water. After a seven day acclimation period, they were randomly assigned to different experimental groups.

\section{Animal model}

The animals were randomized to four groups and given ad libitum access to one of the following diets: standard chow (control, $\mathrm{n}=7$ ), standard chow supplemented with $4 \mathrm{mg} / \mathrm{kg} /$ day RSG (RSG, $n=8$ ), a diet high in fructose (fructose-fed, $n=9$ ), a diet high in fructose with $4 \mathrm{mg} / \mathrm{kg} /$ day RSG (fructose + RSG, $\mathrm{n}$ $=9) .{ }^{[20]}$ The fructose content provided $60 \%$ of the total calories in the diet prepared in the laboratory as follows: $(\mathrm{g} / \mathrm{kg})$ casein high protein 207.0; DL-methionine 3.0; fructose 600.0; lard 50.0; cellulose 79.81; mineral mix 50.0; zinc carbonate 0.04 ; vitamin mix 10. The amount of RSG to be mixed with chow was calculated depending upon the average quantity of chow diet consumed by each rat in 24 hours.

Animals were maintained on these regimens for three weeks and the systolic blood pressure and body weights were measured weekly. At the end of the third week, food was withdrawn for $16 \mathrm{~h}$ and about 3-4 ml of blood was collected through the retro-orbital plexus under light ether anaesthesia. Blood samples were immediately centrifuged (3000 g for 20 $\mathrm{min}$ ) and commercial kits used to assay plasma for glucose by GOD / POD method [Span Diagnostic Ltd. Sachin, Surat]) as well as for cholesterol and triglycerides by an enzymatic method [Accurex Bio systems, Mumbai and Crest Bio-systems, Goa respectively]). Plasma insulin was measured using a standard radioimmunoassay kit (07260102; ICN Pharmaceuticals Costa Mesa). The degree of IR was estimated using Homeostasis Model Assessment (HOMA) as follows:

Index of insulin resistance $=[$ insulin (in $\mu \mathrm{U}$ ) $\mathrm{X}$ glucose (in $\mathrm{m} \mathrm{mol} / \mathrm{L})] / 22.5 .{ }^{[21]}$

The rats were then exsanguinated and the hearts isolated for autonomic responsiveness study.

Measurement of blood pressure

Systolic blood pressure was measured in conscious rats by the tail cuff method. ${ }^{[22]}$ All the rats were preconditioned to the experimental conditions before actual measurements were conducted. At the time of the experiment, the rats were placed in a constant temperature chamber $\left(32^{\circ} \mathrm{C}\right)$ for $30 \mathrm{~min}$. Thereafter, each animal was placed in a rat holder, the tail cuff and pulse sensor was placed on the tail and connected to a blood pressure transducer (Harvard Apparatus), which in turn was connected to a computer that displayed the blood pressure. Systolic blood pressure was measured at the point where the reappearance of pulsations was detected by the pulse sensor., Eight readings were obtained for each rat. The highest and the lowest measurements were rejected and the average of the remaining was taken as systolic blood pressure of that individual rat.

\section{Isolated right atrial preparation}

The hearts were rapidly removed from the exsanguinated rats and placed in a beaker containing Krebs-Henseleit buffer. After expressing the blood from the heart, the ventricle tissue, fat and connective tissue were trimmed off. The right atrium was isolated and immediately placed in a beaker containing ice-cold oxygenated Krebs-Henseleit buffer, $\mathrm{pH} 7.4$ and gassed with 95\% $02: 5 \% \mathrm{CO}_{2}$. The composition of the Krebs-Henseleit buffer was $(\mathrm{mmol} / \mathrm{L}) \mathrm{NaCl} 124 ; \mathrm{KCl} 4.75 ; \mathrm{MgCl}_{2} 1.30 ; \mathrm{CaCl}_{2} 2.25 ; \mathrm{NaHCO}_{3}$ 25:0 $\mathrm{NaH}_{2} \mathrm{PO}_{4} 0.6$ and Dextrose 10:0. The right atrium was then suspended vertically in a $20 \mathrm{ml}$ tissue bath containing the above medium. One end of the atria was attached to a tissue holder and the other end was mounted by a silk thread to an isometric force transducer (BioPac TSD 104 A Santa Barbara, California) connected to a computerized data acquisition system (BioPac Systems, Inc. MP100A-CE Santa Barbara, California). The atria were allowed to beat spontaneously and were equilibrated at $37^{\circ} \mathrm{C}$ for $60 \mathrm{~min}$. The Krebs bicarbonate solution was replaced every $15 \mathrm{~min}$. Resting tension of $1 \mathrm{~g}$ in the tissue was maintained throughout the experiment.

Experiments were designed to evaluate the effect of IR on the chronotropic responsiveness of the atrial tissue to adrenergic and cholinergic agonists. Cumulative dose-response curves for the adrenergic agonists (norepinephrine and isoproterenol) and the cholinergic agonists (acetylcholine and carbachol) were obtained by sequential addition of drug to the bathing medium. The changes in atrial rate due to the adrenergic and cholinergic drugs were recorded. Preparations used for adrenergic and cholinergic studies were isolated from the same animals. When cumulative dose-response curves were being obtained, the next higher concentration of the agonist was added to the bath solution only after the tissue gave a steady-state response at the previous level for about 60-90 seconds.

\section{Materials}

Acetylcholine chloride, carbachol chloride, dl- isoproterenol hydrochloride and dl-norepinephrine bitartrate were purchased from Sigma Chemicals (St.Louis, MO, USA). RSG was a gift sample from Dr. Reddy's Laboratory Ltd., Hyderabad, India. All other chemicals were reagent grade. Stock solutions of adrenergic and cholinergic agonists were prepared in $1 \%$ ascorbic acid and 5\% sodium dihydrogen orthophosphate solution respectively; further dilutions were made with KrebsHenseleit solution.

Statistical analysis

Data are expressed as the mean $\pm \mathrm{SE}$ (standard error). 
Statistical analysis was carried out using one-way analysis of variance (ANOVA) followed by Bonferroni multiple comparison test or by Student's t-test wherever appropriate. The maximum response produced by the agonists (Emax) and half-maximal effective concentration (EC50) values were obtained by graphical evaluation of individual dose-response curves using statistical software GraphPad Prism (Graph pad Software). P $<0.05$ was considered to be statistically significant.

\section{Results}

\section{General characteristics of animals}

All four treatment groups gained weight to a similar extent over the study period without any significant differences [Table 1]. At the end of the experimental period, fructose-fed rats showed a significant increase in levels of fasting insulin $(P<$ $0.001)$ and triglyceride $(P<0.05)$ as well as the IR index $(P<$ 0.001). Treatment with RSG completely restored these values in fructose-fed rats. Fasting glucose and total cholesterol levels did not differ in control and fructose-fed rats. In fructose-fed rats, the systolic blood pressure increased significantly from the second week onwards and remained elevated till the end of the experimental period. Intake of RSG even with the high fructose diet completely prevented the development of hypertension in fructose-fed rats. RSG did not however, affect any of these parameters in control rats.

\section{Responsiveness of Spontaneous Pacemaker}

\section{Basal rate of spontaneous pacemaker}

There was a reduction in the basal pacemaker rate (right atria) in fructose-fed rats $(P<0.05)$ [Table 2]. The depression in the atrial rate associated with insulin resistance was reversed with RSG treatment. However, here was no alteration in the atrial rate in RSG-supplemented control chow-fed rats [Table 2].

\section{Adrenergic responsiveness}

Both norepinephrine and isoproterenol produced similar chronotropic responses when applied to the atria of the rats of the four groups. While there were no significant differences in the maximal atrial pacemaker rates after application of norepinephrine and isoproterenol in the control, chow + RSG and fructose-fed rats, administration of RSG along with the high fructose diets results in an increase in these atrial rates.

\section{Cholinergic responsiveness}

The isolated atrial preparation from high fructose-fed rats showed an enhanced sensitivity to acetylcholine as seen with the leftward shift in the dose-response curve [Figure 1; Table 3]. The increased sensitivity to acetylcholine was restored to control levels by RSG treatment. In contrast, responsiveness to carbachol (a cholinergic agonist not readily metabolised by acetylcholinesterase) was not affected by high fructose diet-induced IR or RSG treatment as seen with acetylcholine. The maximum spontaneous rates were found to be unchanged in control and fructose-fed rats during exposure to the cholinergic agonists. However, there was a slight increase in these rates after application of acetylcholine and carbachol in RSG-treated rats as compared to the rats of the corresponding groups not receiving RSG.

Figure 1: Effect of acetylcholine on spontaneous rate in right atria isolated from control, rosiglitazone-treated, fructose-fed and fructose plus rosiglitazone treated insulin resistant rats. Preparations $(n=7-9 /$ group) were isolated three weeks after feeding the respective diets. Dose-dependent effects of acetylcholine were examined by cumulative addition; vertical bars represent \pm SE

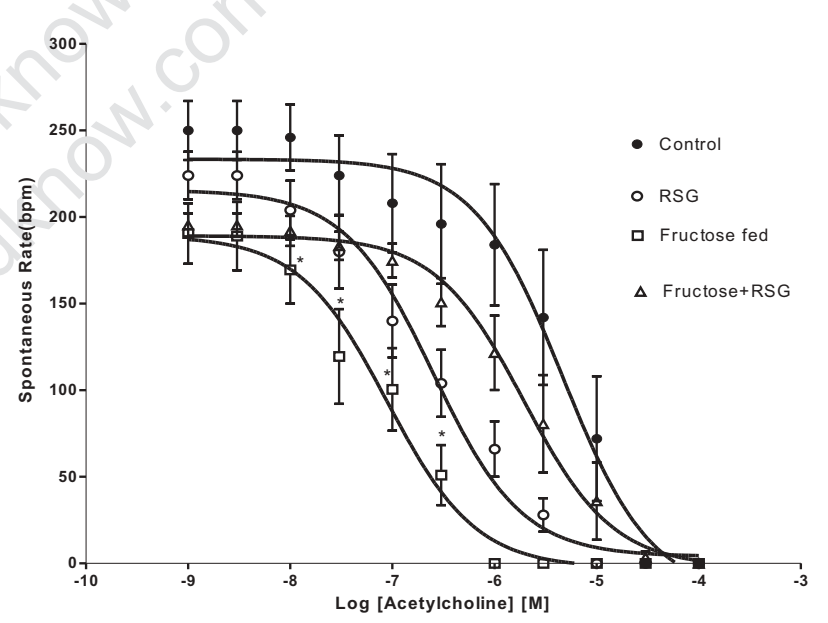

Table 1

General characteristics of the rats in the four experimental groups

\begin{tabular}{|c|c|c|c|c|c|c|c|}
\hline \multirow[t]{2}{*}{ Parameter } & \multirow[t]{2}{*}{ Control } & \multirow[t]{2}{*}{ Chow + RSG } & \multirow[t]{2}{*}{ Fructose-fed } & \multirow[t]{2}{*}{ Fructose + RSG } & \multicolumn{3}{|c|}{ One-way ANOVA } \\
\hline & & & & & $F$ & $d f$, & $P$ value \\
\hline Gain in body weight, $g$ & $65.47 \pm 6.82$ & $59.12 \pm 3.60$ & $55.30 \pm 16.20$ & $60.12 \pm 4.86$ & 11.38, & 3,20 & $>0.05$ \\
\hline Systolic blood pressure, $\mathrm{mm} \mathrm{Hg}$ & $90.4 \pm 16.18$ & $110.2 \pm 6.42$ & $148 \pm 6.70^{*}$ & $106.7 \pm 3.73^{\dagger}$ & 102.6, & 3,20 & $<0.01$ \\
\hline Plasma glucose, mg/dL & $65.94 \pm 5.98$ & $71.60 \pm 5.38$ & $72.56 \pm 4.19$ & $68.39 \pm 2.86$ & 0.811 & 3,20 & $>0.05$ \\
\hline Plasma Insulin, $\mu$ IU/ml & $46.37 \pm 7.32$ & $39.17 \pm 4.75$ & $83.17 \pm 5.54^{*}$ & $52.33 \pm 4.31^{\dagger}$ & 12.17, & 3,20 & $<0.001$ \\
\hline Insulin resistance Index (HOMA) & $6.72 \pm 0.901$ & $7.85 \pm 1.82$ & $16.49 \pm 1.82^{*}$ & $8.79 \pm 0.69^{\dagger}$ & 12.24, & 3,20 & $<0.001$ \\
\hline Plasma cholesterol, mg/dl & $67.17 \pm 3.25$ & $57.33 \pm 4.92$ & $67.1 \pm 3.07$ & $77.17 \pm 1.82$ & 6.59 & 3,20 & $>0.05$ \\
\hline Plasma triglyceride, $\mathrm{mg} / \mathrm{dl}$ & $99.17 \pm 4.02$ & $86.50 \pm 7.99$ & $115.0 \pm 7.01^{*}$ & $88.17 \pm 2.67^{\dagger}$ & 4.99 & 3,20 & $<0.05$ \\
\hline
\end{tabular}

Values are mean $\pm \mathrm{SE} ; \mathrm{n}=7-9$ rats per group; HOMA: Homeostasis model assessment. ${ }^{*} P<0.05$-Significantly different from control group. ${ }^{\dagger} P<0.001$-Significantly different from fructose-fed group 
Table 2

Basal atrial rate, maximum chronotropic responses and $\mathrm{EC}_{50}$ values of nor-epinephrine and isoproterenol in isolated right atria from chow fed and fructose fed rats treated with or without rosiglitazone

\begin{tabular}{|c|c|c|c|c|c|c|c|}
\hline \multirow[t]{2}{*}{ Variable } & \multirow[t]{2}{*}{ Control } & \multirow[t]{2}{*}{ Chow + RSG } & \multirow[t]{2}{*}{ Fructose-fed } & \multirow[t]{2}{*}{ Fructose + RSG } & \multicolumn{3}{|c|}{ One-way ANOVA } \\
\hline & & & & & $\boldsymbol{F}$ & $d f$ & $P$ value \\
\hline Basal rate, beats/min & $205 \pm 7.60$ & $200 \pm 13.7$ & $172 \pm 11.49^{*}$ & $206 \pm 9.33^{\dagger}$ & 3.67, & 3,32 & $<0.05$ \\
\hline \multicolumn{8}{|l|}{ Norepinephrine } \\
\hline Maximum rate, beats/min & $312.2 \pm 12.41$ & $282.1 \pm 4.63$ & $316.9 \pm 6.45$ & $342.4 \pm 7.99$ & 9.31, & 3,29 & 0.05 \\
\hline $\mathrm{EC}_{50}\left(\times 10^{-8}\right)$ & $5.67 \pm 4.13$ & $2.80 \pm 7.99$ & $1.14 \pm 4.47$ & $5.26 \pm 1.27$ & 3.42 & 3,27 & $>0.05$ \\
\hline$\%$ Increase in rate, beats $/ \mathrm{min}$ & $47.89 \pm 5.59$ & $42.11 \pm 1.47$ & $90.56 \pm 14.10^{*}$ & $65.3 \pm 9.26$ & 5.94 & 3,32 & $<0.05$ \\
\hline \multicolumn{8}{|l|}{ Isoproterenol } \\
\hline Maximum rate, beats/min & $294.5 \pm 10.72$ & $288.3 \pm 1.003$ & $290.7 \pm 6.85$ & $310.6 \pm 6.98$ & 2.08 & 3,30 & $>0.05$ \\
\hline $\mathrm{EC}_{50}\left(\times 10^{-7}\right)$ & $4.30 \pm 2.02$ & $1.79 \pm 3.48$ & $2.14 \pm 5.98$ & $2.13 \pm 3.90$ & 1.69 & 3,27 & $>0.05$ \\
\hline$\%$ Increase in rate, beats/min & $43.44 \pm 4.03$ & $44.22 \pm 1.66$ & $72.30 \pm 9.09^{*}$ & $49.89 \pm 4.49$ & 5.70 & 3,33 & $<0.05$ \\
\hline
\end{tabular}

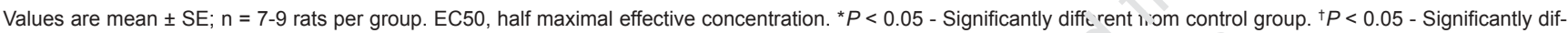
ferent from fructose-fed group

\section{Table 3}

Maximum chronotropic responses and $\mathrm{EC}_{50}$ values for acetylcholine and carbachol in isolated right atria from chow fed and fructose fed rats treated with or without rosiglitazone

\begin{tabular}{|c|c|c|c|c|c|c|c|}
\hline \multirow[t]{2}{*}{ Variable } & \multirow[t]{2}{*}{ Control } & \multirow[t]{2}{*}{ Chow + RSG } & \multirow{2}{*}{\multicolumn{2}{|c|}{ Fr'-n:n'se-fed Fructose + RSG }} & \multicolumn{3}{|c|}{ One-way ANOVA } \\
\hline & & & & & $\boldsymbol{F}$ & $d f$ & $P$ value \\
\hline \multicolumn{8}{|l|}{ Acetylcholine } \\
\hline Maximum rate, beats/min & $198.5 \pm 8.69$ & $211.1 \pm \therefore ? 2 ?$ & $188.9 \pm 17.96$ & $191.5 \pm 6.80$ & 0.78 & 3,25 & $>0.05$ \\
\hline $\mathrm{EC}_{50}\left(\times 10^{-8}\right)$ & $7.48 \pm 3.24$ & $6.14=2.64$ & $1.86 \pm 5.35$ & $5.06 \pm 2.50^{\dagger}$ & 2.47 & 3,25 & $<0.05$ \\
\hline \multicolumn{8}{|l|}{ Carbachol } \\
\hline Maximum rate, beats/min & $175.7 \pm 15.43$ & $?<? .5 \pm 12.12$ & $173.1+i 5.03$ & $198.5 \pm 5.31$ & 3.32 & 3,25 & $>0.05$ \\
\hline $\mathrm{EC}_{50}\left(\times 10^{-8}\right)$ & $6.61 \pm 6.25$ & $3.24 \pm 8.50$ & 2 is -1.37 & $1.78 \pm 6.34$ & 0.97 & 3,24 & $>0.05$ \\
\hline
\end{tabular}

Values are mean $\pm \mathrm{SE} ; \mathrm{n}=7-9$ rats per group. EC50, hi alf maximal effective conce $n$ r. aciun. ${ }^{*} P<0.05$ - Significantly different from control group. ${ }^{\dagger} P<0.05-$ Significantly different from fructose-fed group

\section{Discussion}

A high fructose jisi leads to development of hyperinsulinemia, IR and hypertension within several weeks in rats. ${ }^{[23]}$ Sympatho-e citation has been reported to play an early and in'eg.aı role in the final expression of elevated plasma insulin levels and blood pressure in rats fed with a high fructose diet. ${ }^{\mid 24]}$ Further, acute insulin administration causes hemodynamic changes ${ }^{[9]}$ and an increase in cardiac output. ${ }^{|25|}$ The present study shows that a high fructose diet induces IR and hypertension; is associated with a decline in the basal pacemaker rate and enhanced sensitivity of right atria to acetylcholine but not with any changes in the responsiveness to adrenergic receptor activation.

Several recent reports have suggested that IR in cardiac tissue can be manifested by changes in the function of ion channels. Shimoni et al. ${ }^{[26]}$ have demonstrated that ventricular myocytes from insulin-resistant rats exhibited resistance to the normal ability of insulin to enhance delayed rectifier $\mathrm{K}^{+}$ currents. Further, Dutta et al. ${ }^{[27]}$ have reported that sucroseinduced insulin resistance prolonged electrically stimulated $\mathrm{Ca}^{2+}$ transients in rat cardiomyocytes. The present data provides little information regarding the mechanism for the decline observed in the basal spontaneous pacemaker rate of right atria isolated from fructose-fed rats. Thus, it would seem that changes in ionic currents of the sinoatrial node may modify the spontaneous pacemaker rate.

It is well established that overstimulation of adrenoceptors may induce their desensitization ${ }^{[28]}$ leading to a decrease in receptor density and / or reduction of agonist efficacy. ${ }^{[29]}$ The high plasma epinephrine levels found in this experimental model of hypertension ${ }^{[11]}$ would therefore be expected to alter adrenoceptor-mediated chronotropic responses. However, current data suggests that fructose diet-induced IR does not affect the responsiveness to adrenergic agonists. The maximum spontaneous rate observed in the presence of the selective $\beta$-agonist, norepinephrine, and the nonselective $\beta$-agonist, isoproterenol, was not altered. In addition, no changes in $\mathrm{EC}_{50}$ values of these agonists were observed. This data is consistent with the observations of Kamide et al. ${ }^{[30]}$ wherein the $\beta$-adrenoceptor density was not altered in the left ventricle of fructose-fed insulin resistant rats.

Atrial tissue isolated from insulin resistant rats showed a significant reduction in $\mathrm{EC}_{50}$ values for acetylcholine, whereas the sensitivity to carbachol [a cholinergic agonist not readily metabolised by acetylcholinesterase (AChE)] was not 
significantly affected. In addition, the maximum response to both the agonists was not changed in these tissues indicating no significant change in receptor density or efficacy. An earlier study had suggested that AChE activity can be measured by the pretreatment with di-isopropylflurophosphate (DFP), an irreversible inhibitor of acetylcholinesterase. ${ }^{[31]}$ DFP treatment decreased the basal spontaneous pacemaker rate and abolished the enhanced sensitivity to acetylcholine in diabetic and insulintreated diabetic rats. This data suggests that the enhanced sensitivity to the negative chronotropic action of acetylcholine in fructose-fed rats may be a result of diminished AChE activity.

The autonomic nervous system influences blood pressure and heart rate through baroreceptor mechanisms. A fructosefed rat exhibits insulin resistance, hyperinsulinemia, normal fasting glucose concentration and hypertension. ${ }^{[13]}$ In addition, chronic fructose feeding of rats induces autonomic dysfunction due to impaired vagal reflex activity leading to a decrease in the parasympathetic drive to the heart. ${ }^{[32]}$ Previous reports have shown that chronic hyperinsulinemia is accompanied by cardiac vagal withdrawal in rats ${ }^{[33]}$ and humans. ${ }^{[34 \mid}$ These observations suggest that increased sensitivity of right atria to acetylcholine observed in the present study could be a result of vagal withdrawal. Chronic vagal withdrawal induces muscarinic supersensitivity, developed either to augment or to preserve vagal control of heart.

Dunlap et al. ${ }^{[35]}$ showed that changes in vagal control of the heart at the presynaptic level could lead to upregulation of muscarinic receptors and reduced activity of AChE in the sinoatrial node. We speculate that hypersensitivity of the right atria to acetylcholine in the present study may be the result of decreased AChE activity in response to vagal withdrawal. However, no significant change in muscarinic receptor density was observed in the present study. The use of a muscarinic partial agonist like pilocarpine, whose actions are more sensitive to changes in the receptor number and / or coupling mechanisms, ${ }^{[36]}$ may throw more light on the mechanism of the increased sensitivity of the right atria to acetylcholine in fructose-fed rats.

In the current study, chronotropic response to $\beta$-agonists was unchanged in the right atria of fructose-fed rats but the percentage increases in spontaneous rate (beats/min) after application of the $\beta$-agonists were significantly higher compared to chow-fed rats. These observations indicate an enhanced responsiveness of $\beta$-adrenoceptors to agonists, which could be due to decreased spontaneous basal rate and enhanced sensitivity to parasympathetic stimulation. This notion is supported by the fact that cardiac tissue from a failing heart shows enhanced sensitivity towards sympathetic activation. ${ }^{[34]}$

Steady state hypertension [mean arterial pressure (MAP) $>150 \mathrm{~mm} \mathrm{Hg}$ is also known to impair baroreflex activity. ${ }^{\mid 37,38]}$ Contribution of hypertension to impaired vagal reflexes in fructose-fed rats is unlikely because a high fructose diet does not raise $24 \mathrm{~h} \mathrm{MAP}{ }^{[39]}$ beyond a mild to moderate extent (MAP $<150 \mathrm{~mm} \mathrm{Hg}){ }^{[40]}$ Furthermore, a high fat diet was found to induce hypertension ${ }^{[41]}$ while pressure load-induced cardiac hypertrophy ${ }^{42]}$ has been reported to downregulate cardiac muscarinic receptors. However, no change in Emax was observed in the present study for both Carbachol and Acetylcholine indicating that there was no change in the muscarinic receptor density of atria from fructose-induced insulin resistant hypertensive rats. Taken together, it is conceivable that supersensitivity of right atria to acetylcholine in fructose-fed rats could be due to insulin resistance or hyperinsulinemia. This view is supported by our observations in RSG-treated normal and fructose-fed rats. Treatment with RSG prevented fasting hyperinsulinemia and hypertension in fructose-fed rats. Basal spontaneous rate and autonomic responsiveness of right atrial pacemaker from fructose plus RSG rats were identical to those of the control rats. Furthermore, RSG had no effect on these parameters in control rats. This data supports the view that insulin resistance or hyperinsulinemia may be the cause for observed changes in pacemaker activity.

Insulin resistance is etiologically related to hypertension. In the present study, rosiglitazone was found to decrease blood pressure substantially, which is consistent with the hypothesis that rosiglitazone decreases the blood pressure by improving the insulin resistance. ${ }^{[43]}$ Potential mechanisms for the antihypertensive effect of this drug (other than improvement of insulin resistance) include improved endothelium-dependent vasodilation, decrease in calcium influx and calcium sensitivity of the contractile apparatus ${ }^{[4,45]}$ and inhibition of endothelin-1 expression and secretion (in bovine vascular endothelial cells through activation) of PPAR- $\gamma .{ }^{[46]}$ Rosiglitazone appears to interrupt these sequences and prevents the development of insulin resistance, which probably explains why hypertension did not develop in RSG-treated animals.

Chronic fructose feeding in rats induces hyperinsulinemia, hypertriglyceridemia, insulin resistance and hypertension. ${ }^{[23]}$ Fructose-induced hypertriglyceridemia probably occurs due to decreased catabolism of very low-density lipoproteintriglyceride ${ }^{[47]}$ and / or increased secretion of very-low density lipoprotein-triglyceride in the liver. ${ }^{[4]}$ Further, hypertriglyceridemia induces insulin resistance in skeletal muscle and adipose tissue. ${ }^{[49]}$ Consistent with the actions of the PPAR- $\gamma$ pathway, rosiglitazone, a PPAR- $\gamma$ agonist is reported to increase lipid uptake by the adipose tissue thus reducing triglyceride levels, which leads to increased insulin sensitivity in skeletal muscle and liver. ${ }^{[50]}$

Regardless of the exact mechanism, the supersensitivity of right atria to acetylcholine as indicated by reduction of $\mathrm{EC}_{50}$ values to acetylcholine may be an index of altered control of the vagus on heart rate and this finding may exhibit important clinical implications. Imbalance of the sinoatrial node sensitivity to autonomic neurotransmitters and increased sympathetic activity in insulin resistance may favor the development of cardiac arrhythmia and such conditions might contribute to the increased risk of cardiac death in the state of insulin resistance. ${ }^{[51]}$

To conclude, the fructose-induced insulin resistance and hypertension model presented in this study did not exhibit any changes in the potency or efficacy of $\beta$-adrenoceptors. However, a decrease in basal spontaneous pacemaker rate and enhanced sensitivity to cholinergic agonists might reflect an alternation in the ionic current and cholinesterase enzyme activity respectively. Furthermore, treatment with a clinically relevant insulin sensitiser (RSG) prevents the changes in spontaneous pacemaker rate associated with insulin resistance. Further 
studies are needed to characterize the underlying cellular consequences and factors that contribute to the diminished basal pacemaker rate and enhanced sensitivity to cholinergic agonists.

\section{Acknowledgment}

Authors thank to Dr. F. V. Manvi, Principal, College of Pharmacy and Belgaum for providing necessary facilities. Thippeswamy, B. S. is thankful to Rameshwardasji Birla Smarak Kosh, Medical Research Centre, Bombay Hospital Avenue, Mumbai, for providing fellowship assistance to this project (File No. Fel.2003-2004/ (14).

\section{References}

1. Fontbonne AM, Esehwege EM. Insulin and cardiovascular disease. Paris Prospective study. Diabetes Care 1991;14:461-9.

2. Pyorala M, Miettinen H, Halogen $P$, Laakso M, Pyorala K. Insulin resistance syndrome predicts the risk of coronary heart disease and stroke in healthy middle-aged men: The 22 year follow-up results of the Helsinki policemen study. Arterioscler Thromb Vasc Biol 2000;20:538-44.

3. Celentano A, Vaccaro O, Tammaro P, Galdersi M, Crivaro M, Oliviero M, et al. Early abnormalities of cardiac function in non-insulin-dependent diabetes mellitus and impaired glucose tolerance. Am J Cardiol 1995;76:1173-6.

4. Laakso M, Edelman SV, Brechtel G, Baron AD. Decreased effect of insulin to stimulate skeletal muscle blood flow in obese man. A novel mechanism for insulin resistance. J Clin Invest 1990;85:1844-52.

5. Lopasehak GD, Russdell JC. Myocardial function and energy substrate metabolism in the insulin resistant JCR: LA Corpulent rat. J Appl Physiol 1991;71: 1302-8.

6. Paternostro G, Camici PG, Lammerstma AA, Marinno N, Baliga RR, Kooner JS, et al. Cardiac and skeletal muscle insulin resistance in patients with coronary heart disease. A study with position emission tomography. J Clin Inv 1996;98: 2094-9.

7. Nuutila P, Knuuti J, Ruot Salainen U, Koivist VA, Eronen E, Tenas M, Bergman $\mathrm{J}$, et al. Insulin resistance is localized to skeletal but not heart muscle in type I diabetes. Am J Physiol Endocrinal Metab 1993;264:E756-62.

8. Eckel J, Wirdeier A, Herberg L, Reinauer H. Insulin resistance in the heart: Studies on isolated cardiomyocytes of genetically obese Zucker rats. Endocrine 1985;116:1529-34.

9. Rowe JW, Young JB, Minaker KL, Stevens AL, Pllotta T, Landsberg L. Effect of insulin and glucose infusion, on sympathetic nervous system activity in normal man. Diabetes 1981;30:219-25.

10. Landsberg L. Pathophysiology of obesity-related hypertension. Role of insulin and sympathetic nervous system. J Cardiovasc Pharm 1994;23:51-8.

11. Facchini FS, Stoohs RA, Reaven GM. Enhanced sympathetic nervous system activity. The linchpin between Insulin resistance, hyperinsulinemia and heart rate. Am J Hypertens 1996;9:1013-7.

12. Van De Borne P, Hausberg M, Hoffman RP, Mark AL, Anderson EA. Hyperinsulinemia produces cardiac vagal withdrawal and nonuniform sympathetic activation in normal subjects. Am J Physiol 1999;276:R178-83.

13. Laakso M. Insulin resistance and coronary heart disease. Curr Opin Lipidol 1996;7:217-26.

14. O'Keefe JH Jr, Miles JM, Harris WH, Moe RM, McCallister BD. Improving the adverse cardiovascular plognosis of type-2 diabetes. Mayo Clin Proc 1999;74: $171-80$.

15. Timar O, Scstier F, Levy E. Metabolic Syndrome: A review. Can J Cardiol 2000;16:779-89

16. Anderson EA, Hoffman RP, Balon TW, Sinkey CA, Mark AL. Hyper insulinemia produces both sympathetic neural activation and vasodilation in normal humans. J Clin Invest 1991;87:2246-52.

17. Liao D, Sloan RP, Cascio WE, Folsom AR, Liese AD, Evans GW, et al. Multiple metabolic syndrome is associated with tower heart rat variability: The atherosclerosis risk in communities study. Diabetes Care 1998;21:2116-22.

18. Laitinen T, Vauhkonen IK, Niskanen LK, Hartikainen JE, Lansimies EA, Uusitupa $\mathrm{MI}$, et al. Power spectral analysis of heart rate variability during hyperinsulinemia in non-diabetic offspring of Type-2 diabetic patients: Evidence for possible early autonomic dysfunction in insulin resistant subjects. Diabetes 1999;48:1295-9.

19. Emdin M, Gastaldelli A, Muscelli E, Macerata A, Natali A, Camastra S, et al. Hyperinsulinemia and autonomic nervous system dysfunction in obesity: Effects of weight loss. Circulation 2001;103:513-9.
20. Seda O, Kazdova L, Krenova D, Kren V. Rosiglitazone improves insulin resistance, lipid profile and promotes adiposity in a genetic model of metabolic syndrome $X$. Folia Bilogica (Praha) 2002;48:237-41.

21. Pickavance LC, Tadayyon M, Widdowson PS, Buckingham RE, Wilding JP. Therapeutic index for rosiglitazone in dietary obese rats: Separation of efficacy and haemodilution. Br J Pharmacol 1999;128:1570-6.

22. Deniz DU, Tanju OA, Emine DY. The effect of chronic L-NAME and L-arginine administration on Beta-adrenergic responsiveness of STZ-diabetic rat atria. Pharmacol Res 2000;5:565-70.

23. Hwang IS, Ho H, Hoffman BB, Reaven GM. Fructose-induced insulin resistance and hypertension in rats. Hypertension 1987;10:512-6.

24. Verma S, Bhanot S, McNeill JH. Sympathectomy prevents fructose-induced hyperinsulinemia and hypertension. Eur J Pharmacol 1999;373:R1-4.

25. Baron $A D$. Cardiovascular actions of insulin in humans. Implications for insulin sensitivity and vascular tone. Baillieres Clin Endocrinol Metab 1998;7:961-87.

26. Shimoni $Y$, Severson D, Ewart HS. Insulin resistance and the modulation of rat cardiac K+ currents. Am J Physiol Heart Circ Physiol 2000;279:H639-49.

27. Dutta K, Podolin DA, Davidson MB, Davidoff AJ. Cardiomyocyte dysfunction in sucrose-fed rats is associated with insulin resistance. Diabetes 2001;50:1186-92.

28. Brodde OE. Cardiac beta- adrenergic receptors. Atlas Sci Pharmacol 1987;1: 107-12.

29. Lefkowitz R, Caron MG. Adrenergic receptors: Models of the study of receptors coupled to guanine nucleotide regulatory proteins. J Biol Chem 1998;263:4993-6.

30. Kamide K, Hiromi R, Jitsuo H, Atsunori O, Michiko N, Kouichi M, et al. The reninangiotensin and adrenergic nervous system in cardiac hypertrophy in fructose fed rats. Am J Hypertens 2002;15:66-71.

31. Roterts $\mathrm{CM}$, Konjovic J. Differences in the chronotropic and inotropic response of the rat atrium to choline esters, Cholinesterase inhibitors and certain blocking agents. J Pharmacol Exp Ther 1969;169:109-19.

32. Miller AW, Jason Sims J, Amy Canavan, Theodore, Ujhelyi MR. Impaired vagal reflex activity in insulin resistant rats. J Cardiovasc Pharmacol 1999;33:698702.

33. Bunag RD, Krizsan D, Itoh H. Diminished cardiovascular responsiveness to vagal stimulation in obese rats. Am J Physiol 1990;259:R842-8.

34. Van De Borne P, Hausberg M, Hoffman RP, Mark AL, Anderson EA. Hyperinsulinemia produces cardiac vagal withdrawal and non-uniform sympathetic activation in normal subjects. Am J Physiol 1999;276:R178-83.

35. Dunlap ME, Bibevski S, Rosenberry TL, Ersberger P. Mechanisms of altered vagal control in heart failure: Influence of muscarinic receptors and acetylcholinesterase activity. Am J Physiol Heart Circ Physiol 1995;285:H1632-40.

36. Kenakin T. Efficacy. In: Pharmacological analysis of drug -receptor interaction. Raven Press: New York; 1993. p. 249-78.

37. Head GA. Baroreflex and cardiovascular regulation in hypertension. J Cardiovasc Pharmacol 1995;26:S7-16.

38. Korner PI, West MJ, Shaw J, Uther JB. "Steady-state" properties of the baroreceptor-heart rate reflex in essential hypertension in man. Clin Exp Pharmacol Physiol 1974;1:65-76.

39. Brands MW, Garrity CA, Holman MG, Keen HL, Alonso-Galicia M, Hall JE. High-fructose diet does not raise 24-hour mean arterial pressure in rats. Am J Hypertens 1994;7:104-9.

40. Bhanot S, Mc Neill JH. Insulin and Hypertension: A casual relationship? Cardiovasc Res 1996;31:212-21.

41. Pelat M, Verwaerde P, Merial C, Galitzky J, Berlan M, Montastruc JL, et al. Impaired atrial $\mathrm{M}_{2}$-cholinoceptor function in Obesity-related hypertension. Hypertension 1999;34:1066-72.

42. Vatner DE, Lee DL, Schwarz KR, Longabaugh JP, Fujii AM, Vatner SF, et al. Impaired cardiac muscarinic receptor function in dogs with heart failure. J Clin Invest 1988;81:1836-42.

43. Prescribing information for Rosiglitazone, SmithKline Beecham Pharmaceuticals May 1, 1999

44. Kawasaki J, Hiranok, Nishimura J, Fujishimu M, Kanuide H. Mechanism of vasorelaxation induced by troglitazone, a novel antidiabetic drug, in the porcine coronary artery. Circulation 1998:98:2446-52.

45. Song J, Walsh MF, Igwe R, Ram JL, Barazi M, Dominguez LJ, et al. Troglitazone reduces contraction by inhibition of vascular smooth muscle cell Ca2+ currents and not endothelial nitric oxide production. Diabetes 1997:46:659-64.

46. Satoh H, Tsukamoto K, Hashimoto Y, Hashimoto N, Togo M, Hara M, et al. Thiazolidinediones suppress endothelin-1 secretion from bovine vascular endothelial cells: A new possible role of PPARgamma on vascular endothelial function. 
Biochem Biophy Res Commun 1999;254:757-63.

47. Hirano T, Mamo J, Poapst M, Steiner G. Very-low-density lipoprotein triglyceride kinetics in acute and chronic carbohydrate-fed rats. Am J Physiol 1989;255: E236-40.

48. Zavaroni I, Chen YD, Reaven GM. Studies of the mechanism of Fructose induced hypertriglyceridemia in the rat. Metab Clin Exp 1982;31:1077-83.

49. Nikkila EA, Ojalu K. Induction of hyperglyceridemia by fructose in the rat. Life Sci
1965:4:937-43.

50. Barbier O, Torra IP, Daguay Y, Blamaquart C, Frachart JC, Glinearc C, et al. Pleiotropic actions of peroxisome proliferator-activated receptors in lipid metabolism and atherosclerosis. Arterioscler Tromb Vasc Biol 2002;22:717-26.

51. Curb JD, Rodriguez BL, Burchfiel CM, Abbott RD, Chiu D, Yano K. Sudden death, impaired glucose tolerance and diabetes in Japanese American men. Circulation 1995;91:2591-5. 